\title{
Effect of diabetes mellitus on long-term outcomes of patients with ischemic heart disease and left ventricular dysfunction undergoing surgical revascularization: a propensity score-matching study
}

meng liu

Chinese PLA General Hospital https://orcid.org/0000-0002-7063-0062

Hua-Jun Zhang

Chinese PLA General Hospital

Han Song

Chinese PLA General Hospital

Nan Cheng

Chinese PLA General Hospital

Yuan-Bin Wu

Chinese PLA General Hospital

Rong Wang ( $\nabla$ wangrongdoc@126.com )

Original investigation

Keywords: coronary artery bypass grafting, diabetes mellitus, ischemic heart disease, left ventricular dysfunction

Posted Date: February 12th, 2020

DOI: https://doi.org/10.21203/rs.2.23252/v1

License: (c) (i) This work is licensed under a Creative Commons Attribution 4.0 International License. Read Full License 


\section{Abstract}

\section{Background}

Diabetes mellitus (DM) is an important risk factor in the long-term outcomes of surgical revascularization. However, few studies have focused on patients with left ventricular dysfunction (LVD) and DM, and the results are controversial. This study aimed to evaluate the effect of DM on the long-term outcomes of patients with ischemic heart disease (IHD) and LVD undergoing coronary artery bypass grafting(CABG).

Methods

In this propensity-matched study, patients with IHD and LVD who underwent CABG in our hospital from January 2007 to December 2017 were enrolled. The patients were divided into two groups according to whether they had DM. The primary endpoint was all-cause death, and the secondary endpoint was a composite of all-cause death, stroke, recurrent myocardial infarction, and re-revascularization.

Results

There was no significant difference in all-cause mortality between the two groups(5.78\%vs.4.05\%,P=0.216). The incidence of main adverse cardiovascular and cerebrovascular events(MACCE) in the secondary endpoint was significantly higher in the DM group than in the non-DM group $(10.40 \%$ vs. $8.09 \%, P=0.023)$.

\section{Conclusions}

DM can negatively affect the long-term outcome of patients with IHD and LVD undergoing CABG by significantly increasing the overall incidence of MACCE, though the long-term survival doesn't show significant difference between the DM and non-DM patients.

\section{Background}

Ischemic heart disease (IHD), diabetes mellitus (DM), and heart failure (HF) are serious public health disorders around the world. Among them, IHD is the leading cause of HF ${ }^{[1]}$ while DM plays the critical role in the occurrence, development and long-term outcome of $\mathrm{IHD}$ and $\mathrm{HF}^{[2]}$. Coronary artery bypass grafting (CABG) has been widely accepted as the standard care of treating IHD. For patients with IHD and left ventricular dysfunction (LVD), CABG shows better outcomes than percutaneous intervention and oral medication therapy, and was recommended by the current guidelines as the first treatment choice ${ }^{[3,4]}$. DM has been demonstrated as an independent risk factor for long-term outcomes of CABG by a series of studies $^{[5]}$. However, previous studies on the effect of DM on patients with IHD and LVD undergoing CABG were relatively remote and controversial ${ }^{[6,7]}$. In recent years, with the improvement of patients' compliance of glucose control and the treatment strategy, the long-term survival of patients with DM and 
cardiovascular disease has been significantly improved ${ }^{[8]}$. Additionally, improvement of the CABG technique and the popularity of optimal medical therapy after CABG have significantly improved the longterm outcome of patients with IHD and LVD ${ }^{[9]}$. Therefore, we conducted this single center retrospective study aiming to re-evaluate the effect of DM on the long-term outcomes of patients with IHD and LVD undergoing $C A B G$, and trying to provide contemporary evidence for daily clinical practice.

\section{Materials And Methods 1.1 Patients}

From January 2007 to December 2017, a total of 439 patients with IHD and LVD underwent isolated CABG in our center. Preoperative coronary angiography of the entire group of patients confirmed significant triple vessel disease involving the left anterior descending coronary artery and/or left main disease. Preoperative echocardiography showed that the left ventricular ejection fraction (LVEF) was $\leq$ $50 \%$. Patients were divided into two groups according to whether they had DM. There were 183 patients in the DM group and 256 in the non-DM group. All patients in the DM group received oral medication, insulin, or both before the procedure. Patients who underwent emergency CABG or concurrent procedures (e.g., mitral or aortic valve replacement or left ventricular aneurysm resection) were excluded. Using the propensity score-matching method, preoperative echocardiographic parameters (LVEF, left ventricular end-diastolic dimension LVEDD) were used as the primary matching index, and patients with DM and those without DM were initially selected. The risk factors of the Euroscore (age, sex, etc.) were used as the secondary matching index, and 173 pairs of patients were selected according to the ratio of a 1:1 match and the baseline characteristics were listed in Table 1.

\subsection{Methods}

All the operations were performed under general anesthesia and median sternotomy approach with or without cardiopulmonary bypass according to the surgeons' preference and patients' condition. LIMA was always grafted to the left anterior descending artery if possible and the great saphenous vein was anastomosed to other lesions. All patients received standard dual antiplatelet therapy consisting of $100 \mathrm{mg} / \mathrm{d}$ of aspirin and $75 \mathrm{mg} / \mathrm{d}$ of clopidogrel for at least 1 year. This therapy was combined with statins, angiotensin-converting enzyme inhibitors, §-blocker depending on the patient's blood pressure and heart rate. Patients in the DM group were administered oral hypoglycemic agents or hypodermic insulin or both to control blood glucose levels. All patients were followed up by the out-patient clinic, telephone, or mail.

\subsection{Outcomes}


The primary endpoint was all-cause death, and the secondary endpoint was a composite endpoint of cardiovascular and cerebrovascular adverse events, including death, stroke, myocardial infarction (MI), and revascularization. MI was defined as a ST-segment elevation MI or non-ST-segment elevation $\mathrm{MI}$ at readmission. Stroke was defined as a neurological diagnosis of cerebral hemorrhage or cerebral infarction. Repeated revascularization was defined as revascularization at the time of readmission, including $C A B G$ and percutaneous intervention.

\subsection{Statistical Analysis}

SPSS 19.0 statistical software (SPSS, Inc, Chicago, IL) was used for analysis. All continuous variables are shown as mean \pm SD. Student's t-test was used to compared normal distributed data, non-parametric wilcoxon test was used for comparsion of innormal distributed data. Categorical variables were tested by the chi-square test. Propensity score matching was performed by using SPSS 19.0 statistical software. Primary and secondary outcomes were analyzed by the Kaplan-Meier method, and Kaplan-Meier curves were drawn. The confidence interval $(\mathrm{Cl})$ was $95 \%$ and a statistical difference was considered as $\mathrm{P}<0.05$.

\section{Results}

\subsection{Perioperative outcomes}

The DM group had a mean history of DM for $8 \pm 5.5$ years, a mean glycated serum protein level of $200 \pm$ $40.5 \mu \mathrm{mol} / \mathrm{L}$ (reference value: $125-240 \mu \mathrm{mol} / \mathrm{L}$ ), and a mean glycated hemoglobin level of $6.40 \% \pm 0.72 \%$ (reference value: $4.1-6.5 \%$ ) at admission. On the basis of a diabetic diet, patients in the DM group received oral hypoglycemic drugs $(84.9 \%)$ or subcutaneous insulin injection $(41.6 \%)$ or both to control blood glucose levels at $6 \mathrm{mmol} / \mathrm{L}(5.28 \pm 1.06 \mathrm{mmol} / \mathrm{L})$ during the preoperative period. Patients in the DM group also received continuous insulin infusion at the early postoperative period in the intensive care unit to control blood glucose levels at $6-8 \mathrm{mmol} / \mathrm{L}(6.77 \pm 1.21 \mathrm{mmol} / \mathrm{L})$. There was no significant difference in the proportion of on-pump CABG between the DM and non-DM groups ( $81.5 \%$ vs. $78.0 \%)$. There was no significant difference in the number of target lesions that were treated between the DM and non-DM groups $(2.96 \pm 0.92$ vs. $3.03 \pm 0.82)$. There were also no significant differences in the rates of surgical death, severe ventricular arrhythmia, postoperative renal failure, low cardiac output, respiratory insufficiency, perioperative use of intra-aortic balloon pump(IABP), and cerebrovascular complications between the two groups.(Table 2)

\subsection{Primary Outcome}

Kaplan-Meier analysis showed that the cumulative incidence of all-cause death was not different between the DM and non-DM groups at 5 years ( $5.78 \%$ vs. $4.05 \% \mathrm{P}=0.216)$. (Fig. 2) 


\subsection{Secondary Outcomes}

Kaplan-Meier analysis showed that the incidence of composite endpoint events was significantly higher in the DM group than in non-DM group at 5 years $(10.40 \%$ vs. $8.09 \%, P=0.023)$ (Fig. 1$)$. Cox regression analysis showed that the non-DM group was associated with a significantly lower risk for composite endpoint events compared with the DM group (hazard ratio $=0.605 ; 95 \% \mathrm{Cl}, 0.39$ to $0.94, \mathrm{P}=0.024$ ). There were no significant differences in the other components of composite endpoint events, including stroke ( $2.31 \%$ vs. $3.47 \%)$, Ml ( $0 \%$ vs. $1.16 \%)$, and the incidence of re-revascularization $(2.89 \%$ vs. $0.58 \%)$ at 5 years between the DM and non-DM groups. There were no significant differences in the Kaplan-Meier curves between the groups. (Fig. 2)

\section{Discussion}

The main findings of this study are as follows. Firstly, DM significantly increased the overall composite adverse events in patients with IHD and LVD undergoing CABG. Secondly, the long-term survival between the DM group and non-DM group had no significant difference.

DM has become a high risk factor for heart failure because it is associated with high glycated hemoglobin levels, a high body mass index, use of insulin, and combined coronary artery disease and diabetic nephropathy. ${ }^{[10-12]}$ Meanwhile,DM is closely associated with the occurrence, progress and prognosis of IHD. It is recorded that almost $30 \%$ patients admitted with acute coronary syndrome were complicated with DM and this ratio reached $40 \%$ for patients undergoing CABG ${ }^{[3]}$ Framingham study showed that DM can increase the incidence of death and HF in patients with IHD by two to four times ${ }^{[13]}$. The Finnish National Diabetes Registration Study ${ }^{[14]}$ showed that DM significantly increased the risk of myocardial infarction (MI) in patients with IHD, and $\mathrm{Ml}$ was the leading cause of chronic $\mathrm{HF}$ in these patients. The SOLVD trial also showed that ${ }^{[15]} \mathrm{DM}$ significantly increased the mortality rate and incidence of $\mathrm{HF}$ in patients with ischemic heart failure compared with those non-ischemic heart failure. CABG has been widely accepted as the standard care for patients with IHD. However, previous studies of the effect of DM on the long-term outcome of CABG in treating patients with IHD and LVD are relatively remote and the results are controversial. Therefore, further research in this field needs to be performed.

The effect of DM on long-term outcomes of patients with IHD and LVD undergoing CABG was mainly investigated from the 1980s to 2000. The primary endpoint in these investigations was long-term survival. Morris and Trachiotis et al. reported that DM significantly reduced long-term survival of patients with IHD and LVD undergoing CABG ${ }^{[6,16]}$. However, other studies reported that there was no significant difference in long-term survival between patients with DM and non-DM in this subgroup ${ }^{[7,17,18]}$. The CABG PATCH trial, which was the largest trial during that period, included 900 patients with the LVEF < $35 \%$. The patients were divided to DM group with 344 patients and non-DM group with 556 patients. ${ }^{[19]}$ There was no significant difference in survival between the two groups at a 32-month follow-up, however the incidence of readmission was significantly lower in the non-DM group. ${ }^{[19]}$. Compared with these 
studies, our study was somewhat different both in patient's inclusion and in study design. In patient's inclusion, most of our patients were moderately impaired LVD with a mean LVEF $42 \%$ which was higher than the patients included in previous studies with mean LVEF $\leq 35 \%$. In study design, our study used propensity score matching to eliminate the baseline characteristics bias which were common in previous studies due to the controlled study design. Besides, we set the composite MACCE as the second endpoint except with the all cause death as the primary endpoint. In an average 5-year follow-up, the secondary endpoint did show significant difference between the DM and non-DM patient group. Therefore, our study further extended previous study from the severe LVD patient population to moderate LVD patient population supported by a more reliable statistical approach.

Great progress has been made in comprehensive prevention and treatment of DM in the past 20 years, and mortality from cardiovascular causes in patients with DM has been significantly reduced ${ }^{[20-23]}$. However, DM as a high-risk factor affecting the long-term outcomes of CABG has remained unchanged. Two meta-analyses and a large-scale, controlled study have suggested that DM is an important risk factor that affects long-term survival with CABG and increases adverse events ${ }^{[5,24,25]}$. Studies have shown ${ }^{[26,27]}$ that DM mainly affects the outcome of CABG from anatomical and metabolic aspects. With regard to anatomical aspects, DM can deteriorate the endothelium of the vascular system, including the coronary arteries, and accelerate progression of atherosclerosis and change microvascular structure. DM also increases the burden of atherosclerosis and the number of lipid-rich plaques, which are more likely to rupture ${ }^{[26,27]}$. Thus, the severity and extent of diffuse coronary lesions are significantly worse in patients with $\mathrm{DM}$ and IHD than in those without $\mathrm{DM}^{[28]}$. With regard to metabolic aspects, long-term abnormal glucose metabolism leads to energy metabolism disorders, hypertrophy, degeneration, apoptosis, focal necrosis and fibrosis, and finally, irreversible myocardial remodeling. Additionally, high blood glucose levels increase the activity of the myocardial sympathetic nervous system, activate the renin-angiotensin system, and promote proliferation of fibrosis, which lead to myocardial hypertrophy ${ }^{[29]}$ and induce diabetic cardiomyopathy (DCM) by various factors. DCM is an independent risk factor for HF in addition to IHD and hypertension. Therefore, the coronary anatomy of patients with IHD and DM is more complicated and cardiac function reserve is worse than IHD patients without $\mathrm{DM}$, and this situation is more serious for patients with LVD. Although CABG can effectively improve myocardial blood supply, it may not be able to compensate for coronary artery and myocardial damage caused by DM. As the result, CABG probably can not achieve the same effect in patients with DM as that in patients without DM in improving cardiac function and preventing postoperative adverse events. Despite of this, there were no significant differences in perioperative mortality and in long-term survival between the DM and non-DM groups. This finding suggests that CABG is still a standard treatment for patients with IHD and DM and LVD. This group of patients can obtain relatively good clinical benefits through meticulous preoperative evaluation and perioperative management.

\section{Limitations}


Although our study used the propensity score matching method to balance the differences in baseline characters, the fact that it was a single-center retrospective study and it had a small sample size may affect the final results. Additionally, the degree of LVD in the enrolled patients was different to that in previous studies. Therefore, we could not compare our study with previous studies. Large-scale, multicenter studies or randomized, controlled trials are required to further evaluate the effect of DM on the long-term outcomes of CABG in patients with IHD and LVD.

\section{Conclusion}

DM can negatively affect the long-term outcome of patients with IHD and LVD undergoing CABG by significantly increasing the overall incidence of MACCE, though the long-term survival doesn't show significant difference between the DM and non-DM patients.

\section{Declarations}

\section{Ethics approval and consent to participate}

The present study involved analysis of historical de-identified data; thus, it was exempt from Institutional Review Board approval.

\section{Consent for publication}

Not applicable.

\section{Availability of data and materials}

The data that support the findings of this study are available from Department of Cardiovascular Surgery, PLA General Hospital, but restrictions apply to the availability of these data, which were used under license for the current study, and so are not publicly available. Data are however available from the authors upon reasonable request and with permission of Department of Cardiovascular Surgery, PLA General Hospital.

\section{Competing interests}

The authors declare that they have no competing interests.

\section{Funding}

Not applicable.

\section{Authors' contributions}

$\mathrm{ML}$ and $\mathrm{HJZ}$ collected and analyzed the data and drafted the manuscript together. These two authors have equal contribution to the completion of this study. HS provided expert statistical advice and 
reviewed all the statistical results. NC and YBW provided research advice and were involved in the patient's follow-up. All authors were involved in editing of the manuscript, and read and approved the final version.

\section{Acknowledgements}

We thank Ellen Knapp, PhD, from Liwen Bianji, Edanz Group China (www.liwenbianji.cn/ac), for editing the English text of a draft of this manuscript.

\section{Authors' information}

Meng Liu MD. E-mail: Medivl24@hotmail.com

PLA General Hospital, Department of Cardiovascular Surgery, Institute of Cardiac Surgery Hua-Jun Zhang MD.,PhD.E-mail: hzhang301@outlook.com

PLA General Hospital, Department of Cardiovascular Surgery, Institute of Cardiac Surgery

Han Song PhD.E-mail:songhan_fmmu@163.com

PLA General Hospital, Department of Health Service

Nan Cheng MD.E-mail: cn86919@163.com

PLA General Hospital, Department of Cardiovascular Surgery, Institute of Cardiac Surgery

Yuan-Bin Wu MD.E-mail: ywu301@outlook.com

PLA General Hospital, Department of Cardiovascular Surgery, Institute of Cardiac Surgery

Correspondence to Rong Wang M.D. wangrongdoc@126.com

Department of Cardiovascular Surgery, Institute of Cardiac Surgery, PLA General Hospital

\section{References}

1. Benjamin EJ, Virani SS, Callaway CW, Chamberlain AM, Chang AR, Cheng S, Chiuve SE, Cushman M, Delling FN, Deo R, de Ferranti SD, Ferguson JF, Fornage M, Gillespie C, Isasi CR, Jimenez MC, Jordan LC, Judd SE, Lackland D, Lichtman JH, Lisabeth L, Liu S, Longenecker CT, Lutsey PL, Mackey JS, Matchar DB, Matsushita K, Mussolino ME, Nasir K, O'Flaherty M, Palaniappan LP, Pandey A, Pandey DK, Reeves MJ, Ritchey MD, Rodriguez CJ, Roth GA, Rosamond WD, Sampson UKA, Satou GM, Shah SH, Spartano NL, Tirschwell DL, Tsao CW, Voeks JH, Willey JZ, Wilkins JT, Wu JH, Alger HM, Wong SS, Muntner P, American Heart Association Council on E, Prevention Statistics C and Stroke Statistics 
S. Heart Disease and Stroke Statistics-2018 Update: A Report From the American Heart Association. Circulation. 2018;137(12):e67-e492.

2. Seferovic PM, Petrie MC, Filippatos GS, Anker SD, Rosano G, Bauersachs J, Paulus WJ, Komajda M, Cosentino F, de Boer RA, Farmakis D, Doehner W, Lambrinou E, Lopatin Y, Piepoli MF, Theodorakis MJ, Wiggers H, Lekakis J, Mebazaa A, Mamas MA, Tschope C, Hoes AW, Seferovic JP, Logue J, McDonagh T, Riley JP, Milinkovic I, Polovina M, van Veldhuisen DJ, Lainscak M, Maggioni AP, Ruschitzka F and McMurray JJV. Type 2 diabetes mellitus and heart failure: a position statement from the Heart Failure Association of the European Society of Cardiology. Eur J Heart Fail. 2018;20(5):853-872.

3. Brignole M. 'Ten Commandments' of ESC Syncope Guidelines 2018: The new European Society of Cardiology (ESC) Clinical Practice Guidelines for the diagnosis and management of syncope were launched 19 March 2018 at EHRA 2018 in Barcelona. Eur Heart J. 2018;39(21):1870-1871.

4. Yancy CW, Jessup M, Bozkurt B, Butler J, Casey DE, Jr., Drazner MH, Fonarow GC, Geraci SA, Horwich T, Januzzi JL, Johnson MR, Kasper EK, Levy WC, Masoudi FA, McBride PE, McMurray JJ, Mitchell JE, Peterson PN, Riegel B, Sam F, Stevenson LW, Tang WH, Tsai EJ, Wilkoff BL, American College of Cardiology F and American Heart Association Task Force on Practice G. 2013 ACCF/AHA guideline for the management of heart failure: a report of the American College of Cardiology Foundation/American Heart Association Task Force on Practice Guidelines. J Am Coll Cardiol. 2013;62(16):e147-239.

5. Bundhun PK, Bhurtu A and Yuan J. Impact of type 2 diabetes mellitus on the long-term mortality in patients who were treated by coronary artery bypass surgery: A systematic review and meta-analysis. Medicine (Baltimore). 2017;96(22):e7022.

6. Trachiotis GD, Weintraub WS, Johnston TS, Jones EL, Guyton RA and Craver JM. Coronary artery bypass grafting in patients with advanced left ventricular dysfunction. Ann Thorac Surg. 1998;66(5):1632-9.

7. Kaul TK, Agnihotri AK, Fields BL, Riggins LS, Wyatt DA and Jones CR. Coronary artery bypass grafting in patients with an ejection fraction of twenty percent or less. J Thorac Cardiovasc Surg. 1996;111(5):1001-12.

8. Rawshani A, Rawshani A and Gudbjornsdottir S. Mortality and Cardiovascular Disease in Type 1 and Type 2 Diabetes. N Engl J Med. 2017;377(3):300-301.

9. Ueki C, Miyata H, Motomura N, Sakaguchi G, Akimoto T and Takamoto S. Off-pump versus on-pump coronary artery bypass grafting in patients with left ventricular dysfunction. $J$ Thorac Cardiovasc Surg. 2016;151(4):1092-8.

10. Thrainsdottir IS, Aspelund T, Thorgeirsson G, Gudnason V, Hardarson T, Malmberg K, Sigurdsson G and Ryden L. The association between glucose abnormalities and heart failure in the populationbased Reykjavik study. Diabetes Care. 2005;28(3):612-6.

11. Green JB, Bethel MA, Armstrong PW, Buse JB, Engel SS, Garg J, Josse R, Kaufman KD, Koglin J, Korn S, Lachin JM, McGuire DK, Pencina MJ, Standl E, Stein PP, Suryawanshi S, Van de Werf F, Peterson 
ED, Holman RR and Group TS. Effect of Sitagliptin on Cardiovascular Outcomes in Type 2 Diabetes. N Engl J Med. 2015;373(3):232-42.

12. White WB, Cannon CP, Heller SR, Nissen SE, Bergenstal RM, Bakris GL, Perez AT, Fleck PR, Mehta CR, Kupfer S, Wilson C, Cushman WC, Zannad F and Investigators E. Alogliptin after acute coronary syndrome in patients with type 2 diabetes. N Engl J Med. 2013;369(14):1327-35.

13. Kannel WB, Ho K and Thom T. Changing epidemiological features of cardiac failure. Br Heart J. 1994;72(2 Suppl):S3-9.

14. Haffner SM, Lehto S, Ronnemaa T, Pyorala K and Laakso M. Mortality from coronary heart disease in subjects with type 2 diabetes and in nondiabetic subjects with and without prior myocardial infarction. N Engl J Med. 1998;339(4):229-34.

15. Shindler DM, Kostis JB, Yusuf S, Quinones MA, Pitt B, Stewart D, Pinkett T, Ghali JK and Wilson AC. Diabetes mellitus, a predictor of morbidity and mortality in the Studies of Left Ventricular Dysfunction (SOLVD) Trials and Registry. Am J Cardiol. 1996;77(11):1017-20.

16. Morris JJ, Smith LR, Jones RH, Glower DD, Morris PB, Muhlbaier LH, Reves JG and Rankin JS. Influence of diabetes and mammary artery grafting on survival after coronary bypass. Circulation. 1991;84(5 Suppl):III275-84.

17. Gill IS, Loop FD, Kramer J, Piedmonte M and Borsh J. Primary isolated coronary artery bypass in left ventricular dysfunction: survival and predictors of survival. Can J Cardiol. 1994;10(9):923-6.

18. Milano CA, White WD, Smith LR, Jones RH, Lowe JE, Smith PK and Van Trigt P, 3rd. Coronary artery bypass in patients with severely depressed ventricular function. Ann Thorac Surg. 1993;56(3):487-93.

19. Whang W and Bigger JT, Jr. Diabetes and outcomes of coronary artery bypass graft surgery in patients with severe left ventricular dysfunction: results from The CABG Patch Trial database. The CABG Patch Trial Investigators and Coordinators. J Am Coll Cardiol. 2000;36(4):1166-72.

20. Lawrie GM, Morris GC, Jr. and Glaeser DH. Influence of diabetes mellitus on the results of coronary bypass surgery. Follow-up of 212 diabetic patients ten to 15 years after surgery. JAMA. 1986;256(21):2967-71.

21. Investigators B. Seven-year outcome in the Bypass Angioplasty Revascularization Investigation (BARI) by treatment and diabetic status. J Am Coll Cardiol. 2000;35(5):1122-9.

22. Mohammadi S, Dagenais F, Mathieu P, Kingma JG, Doyle D, Lopez S, Baillot R, Perron J, Charbonneau E, Dumont E, Metras J, Desaulniers D and Voisine P. Long-term impact of diabetes and its comorbidities in patients undergoing isolated primary coronary artery bypass graft surgery. Circulation. 2007;116(11 Suppl):I220-5.

23. Kappetein AP, Head SJ, Morice MC, Banning AP, Serruys PW, Mohr FW, Dawkins KD, Mack MJ and Investigators S. Treatment of complex coronary artery disease in patients with diabetes: 5-year results comparing outcomes of bypass surgery and percutaneous coronary intervention in the SYNTAX trial. Eur J Cardiothorac Surg. 2013;43(5):1006-13.

24. Zheng J, Cheng J, Wang T, Zhang Q and Xiao X. Does HbA1c Level Have Clinical Implications in Diabetic Patients Undergoing Coronary Artery Bypass Grafting? A Systematic Review and Meta- 
Analysis. Int J Endocrinol. 2017;2017(1537213.

25. Kogan A, Ram E, Levin S, Fisman EZ, Tenenbaum A, Raanani E and Sternik L. Impact of type 2 diabetes mellitus on short- and long-term mortality after coronary artery bypass surgery. Cardiovasc Diabetol. 2018;17(1):151.

26. Moreno PR, Murcia AM, Palacios IF, Leon MN, Bernardi VH, Fuster V and Fallon JT. Coronary composition and macrophage infiltration in atherectomy specimens from patients with diabetes mellitus. Circulation. 2000;102(18):2180-4.

27. Marso SP, Mercado N, Maehara A, Weisz G, Mintz GS, McPherson J, Schiele F, Dudek D, Fahy M, Xu K, Lansky A, Templin B, Zhang Z, de Bruyne B, Serruys PW and Stone GW. Plaque composition and clinical outcomes in acute coronary syndrome patients with metabolic syndrome or diabetes. JACC Cardiovasc Imaging. 2012;5(3 Suppl):S42-52.

28. Ledru F, Ducimetiere P, Battaglia S, Courbon D, Beverelli F, Guize L, Guermonprez JL and Diebold B. New diagnostic criteria for diabetes and coronary artery disease: insights from an angiographic study. J Am Coll Cardiol. 2001;37(6):1543-50.

29. Pappachan JM, Varughese GI, Sriraman R and Arunagirinathan G. Diabetic cardiomyopathy: Pathophysiology, diagnostic evaluation and management. World J Diabetes. 2013;4(5):177-89.

\section{Tables}

Due to technical limitations, the tables are only available as a download in the supplemental files section.

\section{Figures}




\section{Figure $1 \quad$ DM group associated with a worse long-term outcomes}

\section{MACCE}

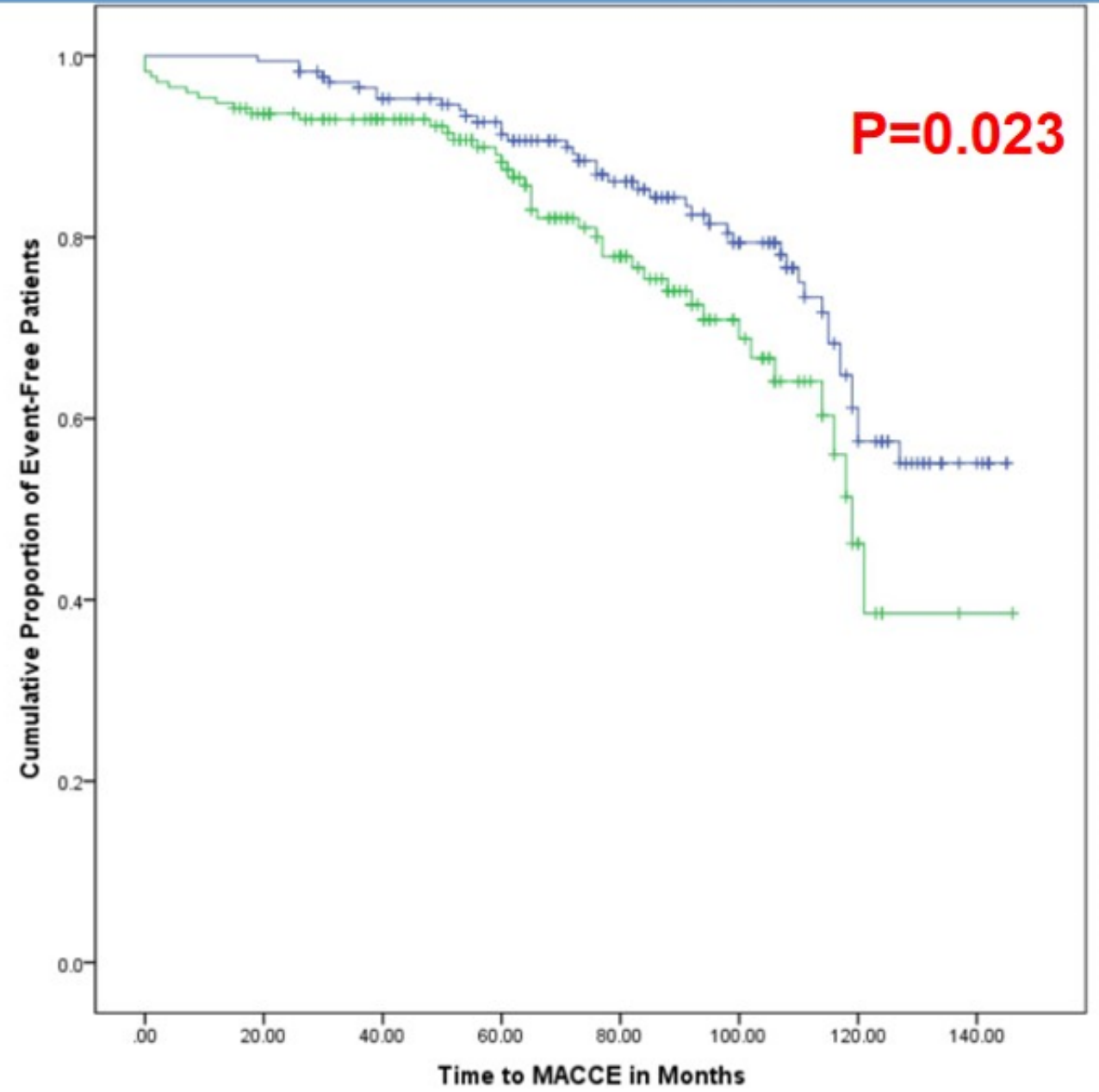

First Treatment Post Index Cath

Non-DM Group was associated with a significantly lower risk for a composite endpoint events compared with DM group ( $H R=0.60595 \% \mathrm{Cl}, 0.39$ to0.94, $\mathrm{P}=0.024$ )

\section{Figure 2}

DM group associated with a worse long-term outcomes 
Figure 2 KM curves of primary outcome and components of the composite end point event
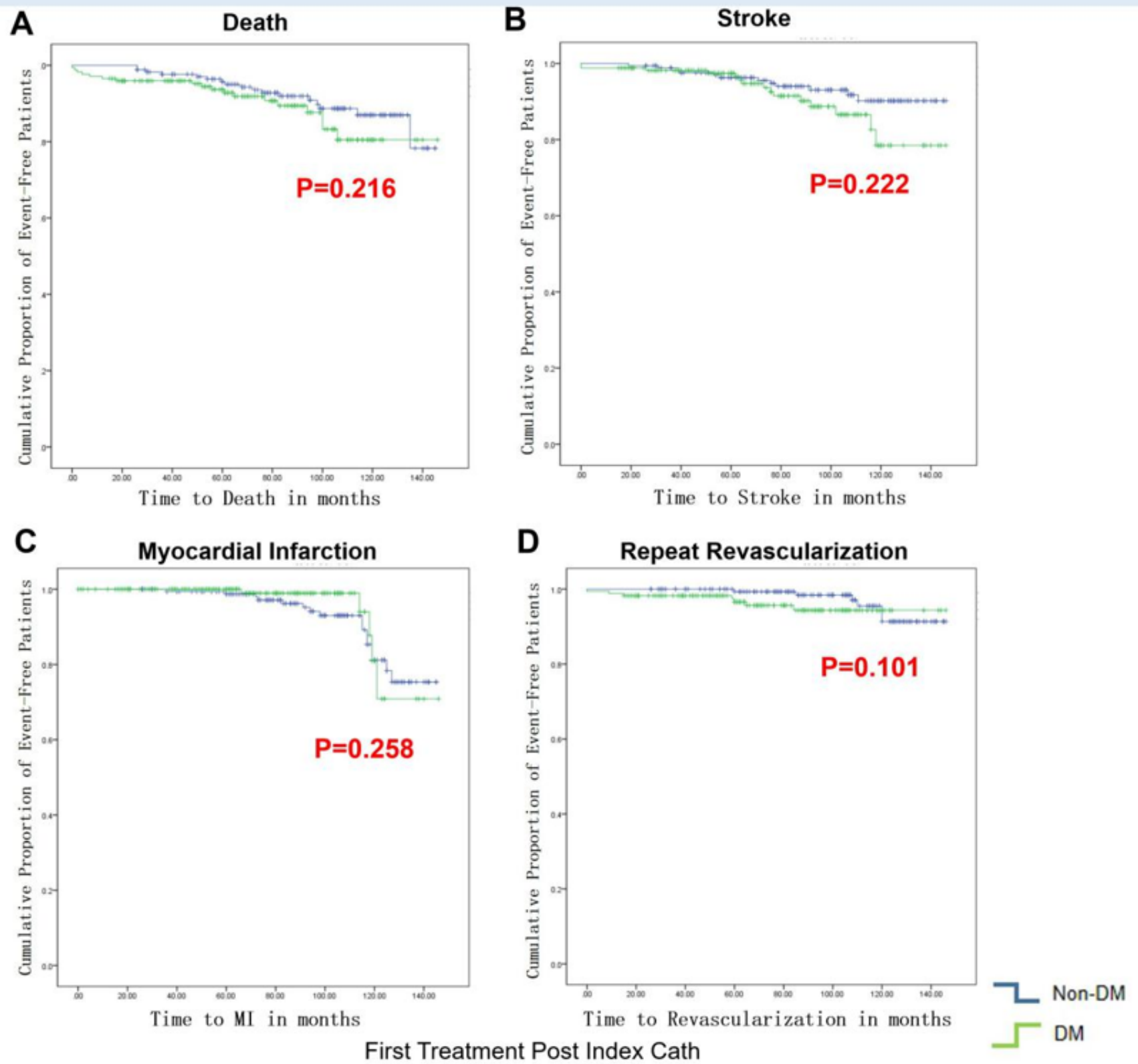

There was no significant difference between DM group and non-DM group in the incidence of Death (A), Stroke (B), MI (C) and revascularization (D)

\section{Figure 4}

KM curves of primary outcome and components of the composite end point event.

\section{Supplementary Files}

This is a list of supplementary files associated with this preprint. Click to download.

- Tables.pdf 
- Tables.pdf

Page 14/14 